\title{
Atividade antimicrobiana do extrato bruto e frações de Glechon spathulata BENTH
}

\author{
Antimicrobial activity of Glechon spathulata BENTH crude extract and fractions
}

\author{
Actividad antimicrobiana del extracto crudo y fracciones de Glechon spathulata BENTH
}

Recebido: 23/11/2021 | Revisado: 29/11/2021 | Aceito: 01/12/2021 | Publicado: 12/12/2021

\author{
Évelin Cogo de Oliveira \\ ORCID: https://orcid.org/0000-0001-7613-3561 \\ Universidade Federal do Mato Grosso, Brasil \\ E-mail: evelin_cogo@msn.com \\ Altevir Rossato Viana \\ ORCID: https://orcid.org/0000-0002-0571-4219 \\ Universidade Franciscana, Brasil \\ E-mail: rossato.viana@hotmail.com \\ Marissa Bolson Serafin \\ ORCID: https://orcid.org/0000-0002-0044-6614 \\ Universidade Federal de Santa Maria, Brasil \\ E-mail: marissabolson@gmail.com \\ Lenise Deon Pompeu \\ ORCID: https://orcid.org/0000-0002-1380-8450 \\ Universidade Franciscana, Brasil \\ E-mail: lenisedeon@gmail.com \\ Melania Palermo Manfron \\ ORCID: https://orcid.org/0000-0002-3857-0629 \\ Universidade Federal de Santa Maria, Brasil \\ E-mail: melaniapalermo@gmail.com
}

\begin{abstract}
Resumo
A espécie medicinal Glechon spathulata Benth pertencente à família Lamiaceae, conhecida como "Manjeroninha-docampo". O objetivo do estudo, foi avaliar a atividade antimicrobiana do extrato bruto e frações obtida em cromatografia em coluna aberta de G. spathulata através do método de microdiluição em caldo, para testar frente a diferentes bactérias gram positivas e gram negativas. De acordo com os resultados obtidos, o maior potencial inibitório ocorreu frente às bactérias gram negativas. As frações $\mathrm{C}$ e $\mathrm{E}$, fração $\mathrm{G}$ e o extrato bruto apresentaram melhores resultados frente a bactérias gram negativas, sendo que o maior potencial inibitório ocorreu frente às duas cepas de Escherichia coli (ATCC 35218 e ATCC 25922). O extrato bruto e as frações C e F apresentaram um maior efeito inibitório frente à Salmonella tiphymurium ATCC 52117. Também houve um potencial inibitório frente às cepas de Staphylococcus aureus ATCC 25923, tanto pelo extrato bruto, como pelas frações C e B e frações F e G. A inibição das cepas de Staphylococcus epidermidis ATCC 12228 ocorreu somente no extrato bruto e nas frações de acetato de etila. Tanto o extrato bruto quanto as frações de G. spathulata apresentaram potencial atividade antibacteriana. $\mathrm{O}$ extrato e as frações apresentaram melhor atividade frente à cepa de Salmonella tiphymurium quando comparado a estudos que utilizaram a mesma planta e plantas da mesma família. Este estudo mostrou que tanto o extrato bruto, quanto algumas frações de Gelchon spathulata Benth são candidatos potenciais para o desenvolvimento de novos agentes antimicrobianos.
\end{abstract}

Palavras-chave: Glechon spathulata; Lamiaceae; Concentração Inibitória mínima; Bactérias gram positivas e gram negativas.

\begin{abstract}
The medicinal species Glechon spathulata Benth, belonging to the family Lamiaceae, known as the "Mangeroninhado-campo". The objective of the study was to evaluate the antimicrobial activity of the crude extract and fractions obtained in open - column chromatography of G. spathulata through the broth microdilution method, to test against different gram positive and gram-negative bacteria. According to the results obtained, the greatest inhibitory potential occurred against gram negative bacteria. The fractions $\mathrm{C}$ and $\mathrm{E}, \mathrm{G}$ fraction and crude extract presented better results against gram negative bacteria, and the highest inhibitory potential occurred in relation to the two strains of Escherichia coli (ATCC 35218 and ATCC 25922). The crude extract and C and F fractions showed a greater inhibitory effect against Salmonella tiphymurium ATCC 52117. There was also an inhibitory potential against Staphylococcus aureus strains ATCC 25923, both for the crude extract, as well as fractions C and B And fractions F and G. Inhibition of Staphylococcus epidermidis strains ATCC 12228 occurred only in crude extract and ethyl acetate fractions. Both the crude extract and the fractions of G. spathulata presented a potential antibacterial activity. The extract and the fractions presented better activity against the strain of Salmonella tiphymurium when compared to
\end{abstract}


studies that used the same plant and plants of the same family. This study showed that both the crude extract and some fractions of Glechon spathulata Benth are potential candidates for the development of new antimicrobial agents. Keywords: Glechon spathulate; Lamiaceae; Minimum inhibitory concentration; Gram positive and gram negative bactéria.

\begin{abstract}
Resumen
La especie medicinal Glechon spathulata Benth perteneciente a la familia Lamiaceae, conocida como "Manjeroninhado-campo". El objetivo del estudio fue evaluar la actividad antimicrobiana del extracto crudo y fracciones obtenidas por cromatografía en columna abierta) de G. spathulata mediante el método de microdilución en caldo, para contrastar diferentes bacterias gram positivas y gram negativas. Según los resultados obtenidos, el mayor potencial inhibitorio se presentó frente a bacterias gram negativas. Las fracciones C y E, la fracción G y el extracto crudo mostraron mejores resultados contra bacterias gramnegativas, con el mayor potencial inhibitorio ocurriendo contra las cepas de Escherichia coli (ATCC 35218 y ATCC 25922). El extracto crudo y las fracciones C y F mostraron un mayor efecto inhibidor frente a Salmonella tiphymurium ATCC 52117. También existió un potencial inhibitorio frente a cepas de Staphylococcus aureus ATCC 25923, tanto para el extracto crudo como para las fracciones C y B y fracciones F y G. La inhibición de las cepas de Staphylococcus epidermidis ATCC 12228 se produjo sólo en el extracto crudo y en las fracciones de acetato de etilo. Tanto el extracto crudo como las fracciones de G. spathulata mostraron una potencial actividad antibacteriana. El extracto y las fracciones mostraron una mejor actividad contra la cepa de Salmonella tiphymurium en comparación con los estudios que utilizaron la misma planta y plantas de la misma familia. Este estudio mostró que tanto el extracto crudo como algunas fracciones de Gelchon spathulata Benth son candidatos potenciales para el desarrollo de nuevos agentes antimicrobianos.
\end{abstract}

Palabras clave: Glechon spathulata; Lamiaceae; Concentración mínima inhibitoria; Bacterias gram positivas y gram negativas.

\title{
1. Introdução
}

No Brasil existem alguns grupos culturais como índios, pessoas que vivem em zonas rurais, que recorrem às plantas medicinais para o tratamento e cura de doenças. Cada um destes grupos colabora para o conhecimento da população em geral. Assim, a vasta biodiversidade biológica existe para contribuir para na evolução e produção de medicamentos obtidos a partir de plantas medicinais (Saklani, Kutty, 2008; Battisti et al., 2013). Conforme descrito pela (OMS), aproximadamente 80\% da população de países que estão em desenvolvimento, utilizam as plantas medicinais como única forma de acesso aos cuidados básicos de saúde, mostrando a importância de estudos com plantas medicinais para a população (Corrêa, Rodrigues e Barbano, 2016). A espécie Glechon spathulata Benth, inserida na família Lamiaceae, a qual possui 14 espécies distribuídas entre Brasil e Paraguai, popularmente conhecida como manjeroninha-do-campo, no qual é empregada na culinária, devido seu aroma ser semelhante ao tempero manjerona (Origanum majorana), estudos com esta planta até o presente momento são insuficientes para torná-la um medicamento apesar de ser usada há anos na medicina tradicional como digestiva, expectorante, antisséptica e diaforética (Coimbra, 1942; Mentz, Lutzemberger e Schenkel, 1997; Xifreda e Mallo, 2004; Brandão, Cosenza, Moreira e Monte-Mor, 2006). Uma pesquisa da Organização das Nações Unidas (ONU) revelou que, até 2050, 10 milhões de pessoas no mundo poderão morrer a cada ano devido a doenças resistentes a medicamentos. A ONU publicou um relatório reconhecendo que a questão da resistência antimicrobiana envolve aspectos relacionados a saúde humana, animal, alimentar e ambiental. Tal relatório recomenda aos países:

Priorizar planos de ação nacionais para ampliar os esforços de financiamento e capacitação; Implementar sistemas regulatórios mais fortes e apoiar programas de conscientização para o uso responsável e prudente de antimicrobianos por profissionais de saúde humana, animal e vegetal; Investir em pesquisa e desenvolvimento de novas tecnologias para combater a resistência antimicrobiana; Eliminar com urgência o uso de antimicrobianos significativamente importantes como promotores de crescimento na agricultura (ONU, 2019).

Essa resistência pode ser devido a elevada capacidade de mobilizar genes de resistência, sendo consequência do uso incorreto de medicamentos antimicrobianos, sendo necessário a busca de alternativas terapêuticas contra bactérias, e com isso o uso de extratos vegetais vem alcançando uma grande importância (Ingen et al., 2012; Boligon et al., 2013). 
Com isso, estudos como o de Mendonça, Carneiro e Oliveira (2018), que descrevem a atividade antimicrobiana do extrato hidroalcóolico, utilizando-se da planta da família Lamiacea, são de grande importância para população mundial. O que torna o Brasil com sua vasta e rica biodiversidade e a ascensão do mercado mundial de fitomedicamentos um excelente mercado para ser explorado; Através do planejamento dos governos, da orientação à população, do cultivo, buscando a valorização dos conhecimentos populares para inseri-las, pode se, beneficiar os pesquisadores e as pessoas que fazem uso das plantas medicinais, obtendo assim matérias-primas de qualidade e medicamentos fitoterápicos (Filho, 2010).

\section{Metodologia}

\subsection{Material botânico}

As partes aéreas de G. spathulata foram coletadas no município de Dilermando de Aguiar 29०47'38.1"S 54 03'18.9"W, Rio Grande do Sul, em janeiro de 2014. O material testemunha foi identificado e um Voucher se encontra-se no Herbário do Departamento de Biologia da UFSM, sob registro SMDB 15.061.

\subsubsection{Obtenção do extrato bruto (EB)}

$\mathrm{O}$ material botânico foi seco em estufa de ar circulante à temperatura de aproximadamente $40^{\circ} \mathrm{C}$ e triturado em moinho de facas. O pó obtido foi submetido à maceração hidroalcoólica, com etanol a 70\%, por 30 dias, com renovação do solvente a cada 7 dias e agitação diária. Após esse período, o conteúdo foi filtrado, obtendo-se assim o extrato hidroalcoólico, o qual foi concentrado em evaporador rotatório, à temperatura inferior a $40^{\circ} \mathrm{C}$, a fim de eliminar o etanol e obter o extrato aquoso o qual, foi liofilizado para obtenção do extrato seco (ExS).

\subsection{Cromatografia em coluna aberta}

A cromatografia em coluna, uma técnica usada para separar e purificar compostos, foi usada para separar os diferentes compostos do extrato da planta G. spathulata. Foram utilizados solventes, em ordem de polaridade crescente: hexano, clorofórmio, acetato de etila, butanol, metanol e água. 4 gramas de ExS foi adicionado à coluna de vidro previamente preparada com (320 gramas de sílica gel). Após eluição de cada solvente foram sendo coletadas as 30 frações, com as substancias que foram solúveis neste, as quais receberam a denominação de acordo com o solvente (Oliveira, Ritto, Akisue e Bacchi, 2010).

\subsubsection{Cromatografia em Camada Delgada (CCD)}

O método da cromatografia em camada delgada foi utilizado para reunir os extratos de acordo com sua polaridade e pela medida do fator de retenção (Rf). As 30 frações obtidas na cromatografia em coluna aberta foram depositadas em cromatoplaca. Essa foi introduzida em uma cuba, contendo o eluente acetato de etila, ácido fórmico, ácido acético glacial e água (100:11:11:27). O eluente foi escolhido de acordo com testes realizados para verificar qual migrava melhor as frações Wagner e Bladt (1996). Foi utilizado o revelador de flavonoides ácido oxálico + ácido bórico (15 mL; $5 \mathrm{~mL})$, colocado na estufa por 15 minutos e observada em luz UV. Após a CCD, as frações semelhantes foram juntadas, obtendo-se o total de 5 frações para realização da atividade antibacteriana, onde as frações C, B e E foram as frações acetato de etila e, as frações $\mathrm{F}$ e $\mathrm{G}$ as frações butanólicas. 
Figura 1- CCD das frações de Glechon spathulata. Segundo cada círculo frações, F, B, G, C e E respectivamente.

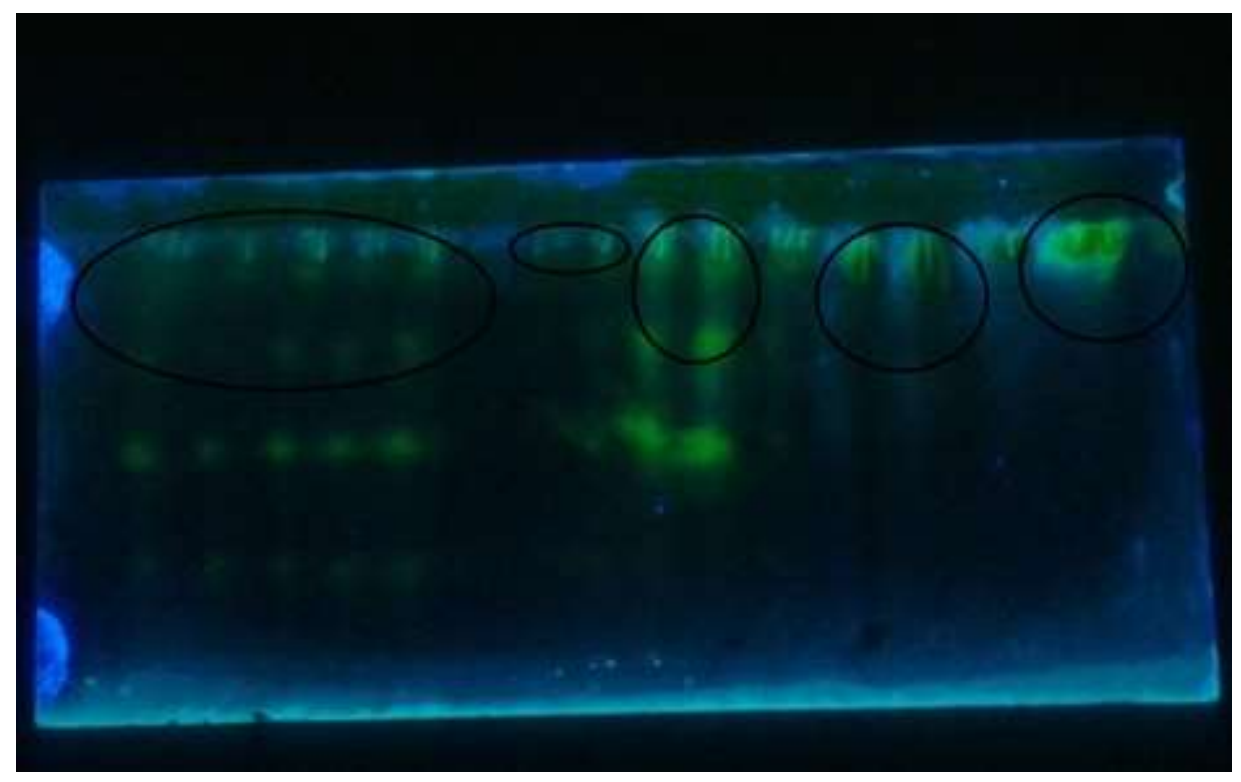

Fonte: Autores.

\subsection{Análise da atividade antibacteriana através da determinação da Concentração Inibitória Mínima (CIM)}

Para a análise da atividade antimicrobiana, foram utilizadas as frações acetato de etila e butanólica, baseado no estudo de Kunz (2007), onde essas frações foram mais eficientes na inibição microbiana. Os testes para determinação da Concentração Inibitória Mínima (CIM) do extrato bruto e frações da G. spathulata foram realizados segundo a metodologia de microdiluição, bastante sensível e desenvolvido por Eloff (1998), onde se verifica a concentração mínima de substância necessária para inibir o crescimento do microrganismo-teste. As amostras foram diluídas em álcool 50\%. Em seguida, preparou-se a suspensão bacteriana na escala 0,5 de McFarland, em tubo contendo solução salina $0,9 \%$, com auxílio de espectrofotômetro (absorbâncias na faixa de 0,08 a 0,1 ). Transferiram-se $40 \mu \mathrm{L}$ da suspensão bacteriana para o tubo de ensaio com inóculo, contendo $3960 \mu \mathrm{L}$ de caldo Muller-Hinton. Em uma placa de 96 poços, foi adicionado ao poço P1 $180 \mu \mathrm{L}$ de caldo Muller-Hinton. Ao poço P1 foi adicionado $20 \mu \mathrm{L}$ de amostra, obtendo-se uma concentração de $3200 \mu \mathrm{g} / \mathrm{mL}$ e iniciaramse, assim, as diluições seriadas até o poço P10, desprezando-se, por fim, $100 \mu \mathrm{L}$. e, então, adicionados mais $100 \mu \mathrm{L}$ de inóculo do poço P1 ao P10, para então completar o total de $200 \mu \mathrm{L}$ no primeiro poço, obtendo-se uma concentração final de 1600 $\mu \mathrm{g} / \mathrm{mL}$ no poço P1; $800 \mu \mathrm{g} / \mathrm{mL}$ em P2; $400 \mu \mathrm{g} / \mathrm{mL}$ em P3; $200 \mu \mathrm{g} / \mathrm{mL}$ em P4; $100 \mu \mathrm{g} / \mathrm{mL}$ em P5; $50 \mu \mathrm{g} / \mathrm{mL}$ em P6; $25 \mu \mathrm{g} / \mathrm{mL}$ em P7; $12,5 \mu \mathrm{g} / \mathrm{mL}$ em P8; 6,25 $\mu \mathrm{g} / \mathrm{mL}$ em P9 e 3,125 $\mu \mathrm{g} / \mathrm{mL}$ em P10.

Para o controle negativo (poço P11), foram utilizados $200 \mu \mathrm{L}$ de caldo Muller-Hinton. No controle positivo (poço P12), foram adicionados $100 \mu \mathrm{L}$ de caldo Muller-Hinton e $100 \mu \mathrm{L}$ de inóculo. Para o controle da amostra, foram utilizados $100 \mu \mathrm{L}$ de caldo Muller-Hinton e $100 \mu \mathrm{L}$ de amostra. Para ambos os controles foram realizadas as mesmas diluições feitas com a amostra. Após, as placas contendo meio de cultura, a amostra e o inóculo bacteriano foram incubadas à $35 \pm 2{ }^{\circ} \mathrm{C}$ por 24 horas e a CIM foi determinada por meio de leitura visual como a concentração capaz de inibir o crescimento bacteriano.

\section{Resultados e Discussão}

Os resultados deste ensaio foram expressos através da Concentração Inibitória Mínima (CIM), ou seja, a menor concentração dos extratos da planta onde estes exercem ação bacteriostática, por leitura visual, sendo os resultados destes ensaios expressos em $\mu \mathrm{g} / \mathrm{mL}$. A Tabela 1 expressa os resultados encontrados. 
Tabela 1 - Valores de Concentração Inibitória Mínima obtidos para o extrato e frações de Glechon sphatulata em avaliação da atividade antimicrobiana.

\begin{tabular}{|c|c|c|c|c|c|c|}
\hline \multicolumn{7}{|c|}{ CIM $(\mu \mathrm{g} / \mathrm{mL})$} \\
\hline Bactérias Gram + & E.B & F.B & F.C & F.E & F.F & F.G \\
\hline Bacillus cereus ATCC 14579 & $>1600$ & $>1600$ & $>1600$ & $>1600$ & $>1600$ & $>1600$ \\
\hline Staphylococcus aureus ATCC 25923 & 800 & 800 & 800 & $>1600$ & 800 & 800 \\
\hline Staphylococcus epidermidis ATCC 12228 & 800 & 800 & 800 & 1600 & 1600 & $>1600$ \\
\hline \multicolumn{7}{|l|}{ Bactérias Gram - } \\
\hline Escherichia coli ATCC 35218 & 200 & 400 & 200 & 200 & 400 & 200 \\
\hline Escherichia coli ATCC 25922 & 800 & 400 & $>1600$ & 400 & 800 & 400 \\
\hline Pseudomonas aeruginosa ATCC 27853 & $>1600$ & $>1600$ & $>1600$ & $>1600$ & $>1600$ & $>1600$ \\
\hline Salmonella tiphymurium ATCC 52117 & 200 & 1600 & 200 & $>1600$ & 400 & $>1600$ \\
\hline
\end{tabular}

E.B: Extrato Bruto. F.B, F.C e F.E: Frações acetato de etila. F.F e F.G: Frações butanol. Fonte: Autores.

De acordo com os resultados obtidos, após eluição de cada solvente foram coletadas 30 frações, conforme solubilidade nesse, recebendo a denominação de acordo com o solvente e pelo método de CCD, sendo que as frações semelhantes foram juntadas, obtendo-se o total de 5 frações para realização da atividade antibacteriana, onde as frações C, B e $\mathrm{E}$ foram as frações acetato de etila e, as frações $\mathrm{F}$ e $\mathrm{G}$ as frações butanólicas. $\mathrm{O}$ maior potencial inibitório ocorreu frente às bactérias gram negativas. As frações C e E (acetato de etila), fração G (butanol) e o extrato bruto apresentaram melhores resultados frente a bactérias gram negativas, sendo que o maior potencial inibitório ocorreu frente às duas cepas de Escherichia coli (ATCC 35218 e ATCC 25922). O extrato bruto e as frações C e F apresentaram um maior efeito inibitório frente à Salmonella tiphymurium ATCC 52117. Também houve um potencial inibitório frente às cepas de Staphylococcus aureus ATCC 25923, tanto pelo extrato bruto, como pelas frações C e B (acetato de etila) e frações F e G (butanólicas). A inibição das cepas de Staphylococcus epidermidis ATCC 12228 ocorreu somente no extrato bruto e nas frações de acetato de etila.

A atividade antimicrobiana foi realizada de forma semelhante ao método utilizado por Kunz (2007) Utilizaram-se as partes aéreas de G. spathulata, enquanto Kunz utilizou partes aéreas e raiz, podendo também ocorrer diferentes resultados dependendo da época de coleta da planta. Segundo Kunz (2007), o extrato bruto de G. spathulata inibiu 100\% do crescimento de bactérias gram positivas e $75 \%$ das gram negativas, mostrando também que as frações butanólicas obtiveram melhor atividade antimicrobiana em bactérias gram negativas. As frações acetato de etila apresentaram atividade em gram positivas. Assim, comparando os resultados frente as cepas de E. coli, eles foram próximos em ambos os estudos.

Na comparação com o estudo realizado por Tepe et al. (2005), onde foi feita a atividade antimicrobiana com óleo essencial com Salvia tomentosa Miller, planta da mesma familia (Lamiaceae), não foi observada atividade antimicrobiana na cepa de E. coli. Segundo Kunz (2007), o óleo essencial apresentou melhor atividade antimicrobiana que o extrato bruto e frações, sendo a atividade antimicrobiana mais efetiva em G. spathulata, mesmo ambas pertencendo a mesma família. O mesmo autor relata que não houve atividade antibacteriana frente a cepa de Salmonella tiphymurium. A atividade antimicrobiana demonstrada no presente estudo apresentou melhor resultado frente a esta bactéria. O possível motivo da diferença de atividade pode ter sido por conta das partes da planta utilizadas.

No estudo de Santuario et al. (2007) foram avaliadas as atividades antimicrobianas do óleo essencial de orégano (Origanum vulgare) e tomilho (Thymus vulgaris), pertencentes à mesma família (Lamiaceae), utilizando diferentes cepas de Salmonella. Observou-se que a atividade antimicrobiana frente à Salmonella tiphymurium não foi significativa comparada com 
os resultados obtidos no presente estudo, onde a atividade apresentada por Origanum vulgare foi de $600 \mu \mathrm{g} / \mathrm{mL}$ e Thymus vulgare foi $1200 \mu \mathrm{g} / \mathrm{mL}$. Assim, a CIM apresentada por G. spathulata foi de $200 \mu \mathrm{g} / \mathrm{mL}$ no extrato bruto e nas frações acetato de etila e $400 \mu \mathrm{g} / \mathrm{mL}$ na fração butanólica. Portanto, foi observada melhor atividade antimicrobiana em G. spathulata, quando comparados com atividades antimicrobianas de outras plantas da mesma família. Estudos têm relacionado o teor de polifenóis com o potencial antimicrobiano de plantas, mas principalmente pela presença de flavonoides (Daglia, 2012). De acordo com Simões (2002), alguns flavonoides e saponinas são responsáveis pela atividade antimicrobiana, sendo estes presentes nos extratos de Glechon spathulata, Kunz (2007).

\section{Considerações Finais}

Por meio dos estudos realizados conclui-se que tanto o extrato bruto quanto as frações de G. spathulata possuem um potencial para atividade antibacteriana. O extrato e as frações foram ativos frente às cepas de E. coli, S. tiphymurium, S. aureus e S. epidermidis, apresentando os melhores resultados frente às cepas gram negativas. $\mathrm{O}$ extrato e as frações apresentaram melhor atividade frente à cepa de Salmonella tiphymurium quando comparado a estudos que utilizam a mesma planta, sendo que apresentou melhor resultado, que pode ser devido à época de coleta, ou até mesmo por neste estudo ser utilizada partes aéreas. Este estudo indica que tanto o extrato bruto, quanto algumas frações de Glechon spathulata Benth são candidatos potenciais para o desenvolvimento de novos agentes antimicrobianos. No entanto, devido à escassez de estudos com esta planta na literatura, é necessária a realização de mais investigações que demonstrem a segurança e eficácia de seu uso em humanos.

\section{Referências}

Battisti, C., Garlet, T. M. B., Essi, L., Horbach, R. K., Andrade, A., Badke, M. R. (2013). Plantas medicinais utilizadas no município de Palmeira das Missões, RS, Brasil. Revista Brasileira de Biociências, 11, 338-348.

Boligon, A. A., Kubica, T. F.,Mario, D. N., Brum, T. F., Piana, M., Weiblen, R., Lovato, L., Alves, S. H., Santos, R. C. V., Alves, C. F. S., Athayde, M. L. (2013). Antimicrobial and antiviral activity-guided fractionation from Scutia buxifolia Reissek extracts. Acta physiologiae plantarum, 35, $2229-2239$.

Brandão, M. G. L.; Cosenza, G. P.; Moreira, R. A.; Monte-Mor, R. L. M (2006). Medicinal plants and other botanicalproducts from the Brazilian oficial pharmacopeia. Revista Brasileira de Farmacognosia, 16, 408-420.

Coimbra, R. (1942). Notas de Fitoterapia. $1^{a}$ edição. Rio de Janeiro, Brasil: Laboratório Silva Araújo.

Corrêa, A. P. R., Rodrigues, A. G., Barbano, D. B. A. (2016). Política e Programa Nacional de Plantas Medicinais e Fitoterápicos. Ministério da Saúde. Recuperado em 20 de janeiro, 2016, em: https://bvsms.saude.gov.br/bvs/publicacoes/politica_nacional_fitoterapicos.pdf

Daglia, M. (2012). Polyphenols as antimicrobial agents. Current Opinion in Biotecnology, 23, (2), 174-181.

Eloff, J. N. A. (1998). Sensitive and quick microplate method to determine the minimal inhibitory concentration of plant extracts for bacteria. Planta Med, 64, (8), 711-713.

Filho, V. C. B. (2010). Controle botânico, físico-químico e atividade anti-inflamatória de Glechon spathulata Benth. (lamiaceae). (Dissertação de mestrado). Universidade Federal de Santa Maria, Santa Maria/RS.

Ingen, J. V., J.; Totten, S. E.; Heifets, L. B.; Boeree, M. J.; Daley, C. L. (2012). Drug susceptibility testing and pharmacokinetics question current treatment regimens in Mycobacterium simiae complex disease. International Journal of Antimicrobial Agents, 39, (2), $173-176$.

Kunz, V. T. (2007). Glechon spathulata Benth.: Estudo fitoquímico e biológico. (Dissertação de mestrado). Universidade Federal de Santa Maria, Santa Maria/RS.

Mendonça, K. F., Carneiro, J. K. R., Oliveira, M. A. S. (2018). Atividade antimicrobiana in vitro do extrato aquoso, hidroalcoólico e alcoólico de folhas de espécies da família Lamiaceae. Rev Pre Infec e Saúde, 4, 7072.

Mentz, L. A.; Lutzemberger, L. C.; Schenkel, E. P. (1997). Da flora medicional do Rio Grande do Sul: Notas sobre a obra de D’Ávila (1910). Caderno de Farmácia, 13, (1), 25-48.

Oliveira, F., Ritto, J. L. A., Akisue, G., Bacchi, E. M. (2010). Fundamentos de cromatografia aplicada a fitoterápicos. São Paulo, Brasil: Atheneu.

Organização Mundial Das Nações Unidas (ONU). (2019). Doenças resistentes a medicamentos poderão causar 10 milhões de mortes por ano no mundo. Nações Unidas Brasil. Recuperado em 01 setembro, 2019, em: https://brasil.un.org/pt-br/83018-doencas-resistentes-medicamentos-poderao-causar-10milhoes-de-mortes-por-ano-no-mundo. 
Research, Society and Development, v. 10, n. 16, e247101623778, 2021

(CC BY 4.0) | ISSN 2525-3409 | DOI: http://dx.doi.org/10.33448/rsd-v10i16.23778

Saklani, A.; Kutty, S. K. (2008). Plant-derived compunds in clinical trials. Drug Discovery Today, 13, 161-171.

Santuario, J, M; Santuario, D, F; Pozzatti, P; Morais, C; Franchin, P, R; Alves, S, H. (2007). Atividade antimicrobiana dos óleos essenciais de orégano, tomilho e canela frente a sorovares de Salmonella entérica de origem avícola. Ciência Rural, 37, (3), 803-808.

Simões, C.M.O., Scbenkel, E. P. (2002). A pesquisa e a produção brasileira de medicamentos a partir de plantas medicinais: a necessária interação da indústria com a academia. Revista Brasileira de Farmacognosia, 12, (1), 35-40.

Tepe, B; Daferera, D; Sokmen, A; Sokmen, M; Polissiou, M. (2005). Antimicrobial and antioxidant activities of the essential oil and various extracts of Salvia tomentosa Miller (Lamiaceae). Food Chemistry, 90, (3), 333-340.

Veiga, J. V. F.; Pinto. C.; Maciel, M.A. (2005). Plantas medicinais: cura segura. Quím. Nova, 28, 519-528.

Wagner, H., Bladt, S. (1996). Plant drug analysis: a thin layer chromatography atlas $2^{a}$ ed. Berlin: Springer.

Xifreda, C. C.; Mallo, A. C. (2004). Las espécies argentinas de Glechon (Lamiaceae, Mentheae). Darwiniana, 42, 333-346. 